\title{
TIGA PARADIGMA EVALUASI PENDIDIKAN: SEBUAH PETA PERKEMBANGAN
}

\author{
Agung Prihantoro \\ ${ }^{1}$ Pendidikan Agama Islam, Universitas Cokroaminoto Yogyakarta \\ Jl. Perintis Kemerdekaan, Gambiran, Umbulharjo, Kota Yogyakarta 55161 \\ ${ }^{1}$ Email: aprihantoro@ucy.ac.id
}

\begin{abstract}
ABSTRAK
Dalam khazanah evaluasi pendidikan level kelas, terdapat celah penelitian, yakni peta perkembangan tiga paradigma evaluasi pendidikan. Artikel ini bertujuan untuk mengisi cela tersebut dengan mendeskripsikan perkembangan tiga paradigma evaluasi pendidikan, yaitu assessment of learning, assessment for learning dan assessment as learning. Metodologi penelitiannya adalah metodologi penelitian pustaka. Hasil penelitiannya menunjukkan bahwa perkembangan paradigma evaluasi pendidikan dibagi jadi dua, yakni perkembangan awal dan perkembangan lanjut. Perkembangan awalnya berupa harapan sebagian kalangan untuk mengorientasikan evaluasi pendidikan pada aktivitas belajar, bukan pada evaluasi semata. Perkembangan awal ini memunculkan paradigma assessment as learning yang kemudian memperlihatkan perbedaan tiga paradigma evaluasi pendidikan. Perkembangan lanjutnya berupa penerapan assessment as learning bersama assessment of learning dan assessment for learning pada berbagai mata pelajaran atau mata kuliah di berbagai negara. Penerapan ini menghasilkan bukti-bukti empiris ilmiah yang menunjukkan kelebihan dan kelemahan, terutama, AaL, serta pengembangannya ke depan.
\end{abstract}

Kata Kunci: paradigma evaluasi pendidikan; assessment of learning; assessment for learning; assessment as learning

\begin{abstract}
In the field of classroom educational assessment or evaluation, there is a research gap in the development of three educational assessment paradigms: assessment of learning, assessment for learning, and assessment as learning. The paper aims to fill the gap by describing the development. The research methodology employed was literature review. The results indicated that two phases of the development are early and advanced ones. In the early phase, some educational stakeholders hoped to orient educational assessment toward learning, not only assessing. The early phase originated the assessment as learning which showed differences among the three paradigms. In the advanced phase, the assessment as learning together with the assessment of learning and the assessment for learning were applied in various classes in schools and higher education in many countries. The application generated scientifically empirical shreds of evidence of strengths and weaknesses and future progress of particularly the assessment as learning.
\end{abstract}

Keyword: educational assessment paradigm; assessment of learning; assessment for learning; assessment as learning

\section{PENDAHULUAN}

Sudah banyak penelitian tentang tiga paradigma evaluasi atau asesmen pendidikan, tetapi belum ada penelitian yang secara khusus mengkaji peta perkembangan terbaru tiga paradigma itu. Paradigma ini melihat evaluasi atau asesmen pendidikan dalam hubungannya dengan aktivitas belajar (learning), dan evaluasi atau asesmen pendidikan di sini dibatasi dalam konteks evaluasi atau asesmen kelas (classroom assessment). Peta 
perkembangannya berarti awal mula tiga paradigma evaluasi atau asesmen pendidikan dan pertumbuhan selanjutnya.

Dalam tulisannya tentang implikasi-implikasi tiga paradigma asesmen pendidikan (assessment of learning [AoL], assessment for learning [AfL], assessment as learning [AaL]) pada penelitian, Chong (2017) menyinggung peta perkembangan ketiga paradigma itu, tetapi dia berfokus pada implikasi-implikasinya. Serafini (2001) juga memaparkan tiga paradigma asesmen pendidikan, tetapi tidak secara khusus memetakan perkembangannya. Tiga paradigma asesmen pendidikan yang dipaparkan Serafini agak berbeda dengan yang ditulis Chong. Serafini menyebut assessment as measurement, assessment as procedure, dan assessment as inquiry. Chong dan Serafini menyebutnya dengan istilah paradigma (paradigm) dan memakai kata assessment, bukan evaluation.

Stiggins (2002) menunjukkan krisis asesmen pendidikan dengan menjelaskan dampak-dampak negatif dari AoL dan menawarkan AaL sebagai solusinya. Senada dengan Stiggins, Earl (2003) membahas AoL, AfL dan AaL dalam bukunya yang berfokus pada AaL dan ia memperbarui bukunya dengan menerbitkan edisi kedua (2013). Kemudian, Earl dan Katz (2006) membahas AfL, AaL dan AoL dan rancangan penerapannya secara cukup banyak, tetapi tidak meng-update perkembangan-perkembangan terbaru dari tiga paradigma tersebut. Earl dan Katz menyebutnya tidak dengan istilah paradigma, melainkan dengan istilah kategori (category) dan kerangka pikir (framework).

Berikutnya, Falchikov (2005) memperlihatkan kelemahan-kelemahan asesmen tradisional dan menjelaskan empat paradigma asesmen: assessment as measurement, assessment as procedure, assessment as enquiry dan assessment as quality control. Istilahistilah yang dipakai Falchikov ini serupa dengan yang dipakai oleh Serafini (2001). Dalam konteks tulisan ini, Falchikov belum memutakhirkan bukunya dengan perkembanganperkembangan terbaru dalam evaluasi pendidikan.

Selanjutnya, MacMath, Wallace dan Chi (2009) meneliti penerapan AaL, AoL dan AfL oleh guru di sekolah di Amerika Serikat dan menerangkan serba-sedikit perkembangan tiga asesmen tersebut. Lalu, Volante (2010) memaparkan pergeseran dari AoL ke AfL dan AaL dan implikasi-implikasi perubahan praktik belajar dan mengajar di dua sekolah dasar dan menengah di Ontario, Kanada. Sebagian besar guru masih menekankan AoL dibandingkan AfL dan AaL. Penerapan AaL masih menghadapi hambatan-hambatan.

Sementara itu, Mutch (2012) mendedahkan perkembangan kebijakan asesmen pendidikan di Selandia Baru dalam kaitannya dengan tiga paradigma asesmen. Mutch 
mengistilahkannya tiga tipe (type). Sebelumnya, Hume dan Coll (2009) telah meneliti tren penerapan AaL di Selandia Baru yang mengikuti tren internasional. Mutch, Hume dan Coll memaparkan masalah-masalah dan tarik-menarik kebijakan asesmen dalam sistem pendidikan di Selandia Baru. Perubahan kebijakan evaluasi pendidikan juga terjadi di negara dekat Selandia Baru, yakni Australia, dan Cumming, Kleij dan Adie (2019) menjelaskan perubahan kebijakan AfL AaL dan AoL di Negera Kanguru itu.

Di Indonesia, Saefurrohman (2015) meneliti penerapan AaL, AoL dan AfL oleh guru bahasa Inggris di sekolah menengah pertama. Dalam kajian teorinya, sebagaimana penelitian-penelitian serupa, Saefurrohman mengutip tulisan-tulisan tentang tiga asesmen tersebut, tetapi tidak menggambarkan peta perkembangan tiga asesmen tersebut.

Lalu, Lam (2015) menulis ikhtisar tiga paradigma asesmen hanya secara ringkas, tetapi memberi perbedaan yang cukup jelas di antara ketiganya. Dalam tulisannya tentang asesmen portofolio pada kuliah menulis, Lam menamakan AaL, AfL dan AoL sebagai pendekatan (approach). Tiga pendekatan tersebut dibedakan dalam hal definisi, paradigma, fokus, portofolio sebagai pembelajaran menulis, portofolio sebagai alat belajar, portofolio sebagai alat asesmen, sumber umpan balik (feedback), manfaat, dan penerapannya.

Terakhir, Cookson (2017) mengkaji secara kritis enam istilah dalam tiga pasangan: formative dan summative, assessment dan evaluation, dan formative assessment dan assessment for learning. Di sini, Cookson mengulik secara jeli gagasan-gagasan asesmen dan istilah-istilah yang dipakai untuk menjelaskan gagasan-gagasan itu. Namun, dia mengatakan bahwa dirinya dalam tulisan tersebut sengaja tidak meneliti evolusi gagasan dan istilah asesmen dan evaluasi pendidikan. Kemudian, Cookson merekomendasikan istilah evaluation for learning dan formative assessment. Namun, dia tidak menyebut istilah-istilah evaluation of learning (EoL) dan evaluation as learning (EaL), serta singkatan EfL (evaluation for learning).

Para peneliti atau penulis tersebut meriset dan menulis tiga paradigma asesmen atau evaluasi pendidikan: AoL, AfL, AaL atau EoL, EfL, EaL, tetapi tidak secara khusus memetakan perkembangan ketiganya dari waktu ke waktu. Jadi, terdapat celah riset (research gap) (C.G.A., 1970) tentang peta perkembangan tiga paradigma evaluasi pendidikan. Artikel ini mengisi celah riset ini dengan memetakan perkembangan tiga paradigma evaluasi pendidikan dari perspektif AaL/EaL, karena kemunculan AaL/EaL menjadikan perbedaan-perbedaan di antara ketiga paradigma itu lebih jelas. Bagaimanakah peta perkembangan tiga paradigma evaluasi pendidikan menurut perspektif AaL/EaL? Itulah pertanyaan penelitian (research question) yang dijawab dalam artikel ini. 


\section{METODE PENELITIAN}

Untuk menjawab pertanyaan penelitian di atas, artikel ini menggunakan metodologi penelitian pustaka (literature review). Xiao dan Watson (2017) mengistilahkan penelitian pustaka sebagai metodologi penelitian dengan kata-kata stand-alone review. Metodologi penelitian pustaka adalah metodologi penelitian yang berupaya memahami literaturliteratur yang ada dengan cara menjumlahkan (aggregation), atau menafsirkan (interpretation), atau menjelaskan (explanation), atau memadukan (integration) literaturliteratur yang sudah ada (Rousseau, Manning dan Denyer dalam Xiao dan Watson, 2017).

Artikel ini menerapkan metodologi penelitian pustaka narrative review yang merupakan salah satu dari lima sub-jenis metodologi penelitian pustaka. Xiao dan Watson mengelompokkan metodologi penelitian pustaka ke dalam empat jenis, yakni describe (deskriptif, mendeskripsikan), test (tes, pengujian, menguji), extend (pengembangan, mengembangkan) dan critique (kritik, mengkritik) (Xiao dan Watson, 2017). Metodologi penelitian pustaka deskriptif dikelompokkan lagi jadi lima sub-jenis, yaitu narrative review, textual narrative synthesis, metasummary, meta-narrative dan scoping review. Metodologi penelitian pustaka narrative review, sebagaimana kata Xiao dan Watson, menarasikan atau menceritakan literatur-literatur yang diteliti. Xiao dan Watson menambahkan bahwa narrative review tidak terlalu menilai kualitas literatur, tetapi artikel ini tetap mengutamakan kualitas literatur yang diteliti.

Penelitian pustaka narrative review menerapkan, sebagaimana kata Xiao dan Watson, delapan langkah, yaitu (1) merumuskan pertanyaan penelitian, (2) membuat dan memvalidasi protokol atau desain penelitian pustaka, (3) mencari literatur-literatur yang diteliti, (4) menyeleksi literatur-literatur yang telah diperoleh, (5) menilai kualitas literatur, (6) mengekstraksi data, (7) menganalisis dan menyintesiskan data, dan (8) menulis laporan temuan penelitian. Langkah $1-5$ termasuk dalam metode pengumpulan data sedangkan langkah 6-8 merupakan metode analisis data.

Pertanyaan penelitian artikel ini telah dirumuskan pada akhir bagian pendahuluan di atas. Desain penelitian pustaka narrative review untuk menjawab tersebut adalah mencari literatur-literatur ilmiah dengan kata kunci assessment as learning di internet, karena penelitian ini menggunakan perspektif AaL untuk memetakan perkembangan tiga paradigma evaluasi pendidikan. Literatur ilmiah yang dimaksud itu berupa artikel di jurnal ilmiah, makalah seminar dan buku yang mencantumkan judul tulisan, nama penulis, tahun terbit, dan jurnal penerbitnya, nama seminarnya atau penerbit bukunya. Literatur-literatur yang sudah diperoleh diseleksi berdasarkan kualitas uraiannya tentang perkembangan 
AoL/EoL, AfL/EfL dan AaL/EaL. Seleksi ini memilih literatur-literatur yang bersifat ilmiah dan memuat uraian perkembangan yang berkualitas tentang AoL/EoL, AfL/EfL dan AaL/EaL, dan terpilih 42 literatur untuk diteliti. Selanjutnya, data-datanya diekstraksi dengan pengodean (coding), dianalisis dan disintesiskan, serta dibuat laporan.

\section{HASIL DAN PEMBAHASAN}

Peta perkembangan tiga paradigma evaluasi pendidikan dibagi jadi dua tahap. Tahap pertama adalah fase perkembangan awal, dan tahap kedua adalah fase perkembangan lanjut. Perkembangan awal menunjukkan gelombang yang kuat dari sebagian kalangan untuk mengorientasikan aktivitas asesmen atau evaluasi pendidikan pada aktivitas belajar, bukan pada asesmen atau evaluasi semata. Perkembangan awal ini memunculkan ide AaL. Kemudian, pada tahap kedua atau fase perkembangan lanjut, ide AaL bersama AoL dan AfL diterapkan pada berbagai mata pelajaran atau mata kuliah di berbagai negara. Penerapan ini menghasilkan bukti-bukti empiris yang menunjukkan kelebihan dan kelemahan, terutama, AaL, serta pengembangannya ke depan.

\section{Perkembangan Awal}

Perkembangan awal tiga paradigma evaluasi pendidikan ditandai dengan kemunculan ide AaL. AaL ini membedakan dengan jelas antara AoL, AfL dan AaL itu sendiri. Perbedaan ini menunjukkan pergeseran paradigma evaluasi belajar atau evaluasi pendidikan dan juga menunjukkan kebutuhan akan AfL dan AaL atau asesmen formatif. Namun, ini tidak berarti bahwa AoL tidak berguna dan harus dihilangkan, tetapi lebih tepatnya, perlu penerapan ketiganya dalam keseimbangan baru.

Istilah AaL kali pertama dikenalkan oleh Ruth Dann dalam bukunya, Promoting Assessment as Learning: Improving the Learning Process (2002). Ide AaL muncul ketika di Inggris, negara tempat Dann bermukim, diundangkan Education Reform Act 1988 yang menguatkan praktik evaluasi daripada aktivitas belajar. Evaluasi belajar atau evaluasi pendidikan menjadi tekanan (pressure) bagi siswa untuk mendapatkan hasil belajar yang bagus. Kemudian, Dann menggagas evaluasi sebagai aktivitas belajar, bukan sebagai aktivitas evaluasi semata-mata. Namun, Dann tidak menyebut istilah-istilah AoL/EoL dan AfL/EfL.

Setahun berikutnya, Lorna Earl (2003) membedakan dengan terang antara AoL, AfL dan AaL. AoL bertujuan untuk menilai hasil belajar dan melaporkan penilaian hasil belajar kepada siswa dan orang tua siswa. Penilaian itu umumnya membandingkan hasil belajar 
antarsiswa. Penilaiannya dilakukan lazimnya di akhir pelajaran, semester atau program, dan penilaiannya berbentuk tes yang berisi pertanyaan-pertanyaan tentang apa yang telah diajarkan. Hasil penilaiannya berupa simbol huru atau angka. Asumsi yang mendasari AoL adalah mengukur hasil belajar (to measure or to learn). Selama ini, AoL mendominasi sistem pendidikan di seluruh dunia.

Asal usul AoL yang berbentuk tes umumnya dinisbahkan pada pejabat Cina tahun 500 SM yang menyeleksi calon-calon pejabat pemerintah (Rust dan Golombok, 2009). Mereka dites terlebih dahulu sebelumnya untuk menentukan siapa yang pantas menjadi pejabat-pejabat pemerintah Cina. Ini dianggap sebagai awal sejarah asesmen, evaluasi atau tes.

AfL, masih menurut Earl, bertujuan tidak untuk membandingkan hasil belajar para siswa, tetapi untuk menemukan kelebihan dan kelemahan setiap siswa dan memberi umpan balik (feedback) kepada siswa tentang aktivitas-aktivitas belajar mereka selanjutnya. Data tentang kelebihan dan kelemahan setiap siswa digunakan untuk memodifikasi aktivitasaktivitas belajar dan mengajar berikutnya. Evaluasinya berbentuk pemberian tugas-tugas yang dapat memberikan data tersebut dan dilakukan lebih dari sekali tidak di akhir akhir pelajaran, semester atau program. Guru masih menempati posisi sentral dalam AfL. Asumsi yang mendasarinya ialah bahwa evaluasi dapat meningkatkan aktivitas belajar.

AaL menguatkan dan meluaskan peran asesmen formatif untuk meningkatkan aktivitas belajar. Cara menguatkan dan meluaskannya adalah dengan menekankan peran siswa, bukan hanya sebagai kontributor dalam proses asesmen dan belajar, melainkan juga sebagai konektor kritis (critical connector) antara proses asesmen dan proses belajar. Siswa berperan ganda sebagai pelajar atau pemelajar (orang yang belajar) dan sebagai asesor atau evaluator yang aktif dan kritis. Sebagai asesor atau evaluator, siswa menilai kemajuan belajarnya: apa sudah sudah dicapai, apa yang belum dicapai, apa kelebihan dan kelemahan dirinya dalam belajar, apa yang akan dilakukan dalam aktivitas belajar berikutnya. Asumsi yang mendasarinya adalah bahwa swa-evaluasi atau swa-asesmen (self-assessment) merupakan inti dari aktivitas belajar dan evaluasi.

Selanjutnya, Lorna Earl bersama Steven Katz (2006) menulis buku yang menguraikan secara lengkap AfL, AaL dan AoL beserta perencanaan penerapan praktisnya dan contoh-contohnya. Bukunya berjudul Rethinking Classroom Assessment with Purpose in Mind: Assessment for Learning, Assessment as Learning, Assessment of Learning. Buku setebal 112 halaman ini boleh disebut sebagai buku yang paling komprehensif dalam 
menjelaskan tiga paradigma evaluasi pendidikan, latar belakangnya dan detail-detail penerapannya di kelas-kelas.

Kemunculan AaL tidak menafikan AfL dan AoL, melainkan membutuhkan keseimbangan baru dalam menerapkan tiga paradigma itu. Dalam pandangan lama (tradisional), AoL menempati proporsi paling besar, sedangkan AaL menempati proporsi paling kecil. Namun, dalam pandangan baru, AaL mendapatkan proporsi yang paling besar sementara AoL justru memperoleh proporsi yang paling kecil. Jadi, AoL, AfL dan AaL tetap dilaksanakan semua dalam proporsi yang berbeda. Keseimbangan lama dan baru ini divisualisasikan dalam bentuk piramida di buku Earl (2003) dan buku Earl dan Katz (2006) seperti tampak pada Gambar 1.

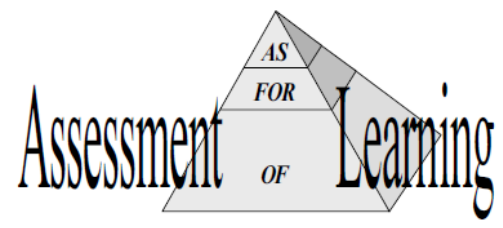

Traditional Assessment Pyramid

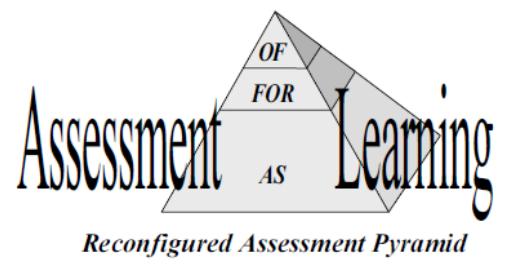

Gambar 1. Keseimbangan Baru dan Keseimbangan Lama antara AoL, AfL dan AoL

(Earl, 2003, \& Earl \& Katz, 2006).

Rita Berry (2008) menulis buku Assessment for Learning yang membabarkan perkembangan-perkembangan evaluasi pendidikan, termasuk AoL dan AaL, terutama di Hong Kong. Cina dan Hong Kong merupakan dua negara yang secara progresif mengikuti isu-isu tiga paradigma evaluasi pendidikan tersebut. Dalam buku ini, Berry mengutip Earl, Black dan Wiliam.

Sejenak mundur ke belakang, setahun sebelum Dann melontarkan ide AaL, Frank Serafini (2001) mengemukakan ide yang senada dengan AoL, AfL dan AaL. Sebagaimana telah disebutkan di muka, Serafini assessment as measurement, assessment as procedure, dan assessment as inquiry. Ide-ide ini memiliki latar belakang serupa bahwa pendidikan dan evaluasi sepantasnya mengarah pada aktivitas belajar. Pendidikan dan pemelajaran tidak berorientasi pada evaluasi.

Latar belakang tersebut bahkan menjauh lagi ke belakang ke pengaruh besar dari Michael Scriven menurut Cookson (2017) dan dari Paul Black dan Dylan Wiliam menurut Chong (2017). Scriven menulis makalah penting bertajuk "The Methodology of 
Evaluation" (1967) yang dipublikasikan oleh Social Science Education Consortium. Dalam tulisan setebal 58 halaman itu, Scriven membedakan antara summative assessment dan formative assessment. Summative assessment kelak diasosiasikan dengan AoL sedangkan formative assessment dengan AfL dan AaL.

Black dan Wiliam juga memberi pengaruh besar pada kelahiran AfL dan AaL. Black dan Wiliam menulis banyak karya, tetapi karya yang dinilai sangat berpengaruh pada ide baru evaluasi pendidikan berjudul "Assessment and Classroom Learning" (1998). Artikel setelah 67 halaman yang dimuat di jurnal ilmiah prestisius Assessment in Education Volume 5 Number 1 ini merupakan penelitian pustaka terhadap lebih dari 250 tulisan. Dalam artikel itu, Black dan Wiliam membayankan bagaimana umpan balik yang dirancangan dengan bagus dari guru kepada siswa berdampak signifikan pada hasil belajar siswa.

Dua puluh tahun setelah publikasi Black dan Wiliam itu, jurnal Assessment in Education Volume 25 Issue 62018 menerbitkan edisi khusus tentang hal ihwal tulisan Black dan Wiliam tersebut. Di edisi ini, Black dan Wiliam juga menulis artikel dengan judul "Classroom Assessment and Pedagogy". Tulisan Black dan Wiliam tak hanya dipuji, tetapi juga dikritik. Hattie (1998) mengkritik tulisan lama Black dan Wiliam bahwa mereka berdua masih berorientasi pada guru ketimbang pada siswa.

\begin{tabular}{|c|c|c|c|}
\hline & Where the learner is going & Where the learner is right now & How to get there \\
\hline Teacher & $\begin{array}{c}1 \text { Clarifying learning } \\
\text { intentions and criteria for } \\
\text { success }\end{array}$ & $\begin{array}{l}2 \text { Engineering effective class- } \\
\text { room discussions and other } \\
\text { learning tasks that elicit } \\
\text { evidence of student } \\
\text { understanding }\end{array}$ & $\begin{array}{l}3 \text { Providing feedback that } \\
\text { moves learners forward }\end{array}$ \\
\hline Peer & $\begin{array}{l}\text { Understanding and sharing } \\
\text { learning intentions and } \\
\text { criteria for success }\end{array}$ & \multicolumn{2}{|c|}{$\begin{array}{l}4 \text { Activating students as instructional resources for one } \\
\text { another }\end{array}$} \\
\hline Learner & $\begin{array}{l}\text { Understanding learning } \\
\text { intentions and criteria for } \\
\text { success }\end{array}$ & \multicolumn{2}{|c|}{5 Activating students as the owners of their own learning } \\
\hline
\end{tabular}

Gambar 2. Langkah Strategis dalam Asesmen (Black \& Wiliam, 2018)

Dalam tulisan barunya ini, Black dan Wiliam mengajukan 5 langkah strategis dalam asesmen (Gambar 2). Pertama, guru (dosen) menjelaskan tujuan belajar dan kriteria keberhasilan belajar. Kedua, guru (dosen) mengadakan diskusi-diskusi kelas yang efektif dengan para siswa (mahasiswa) dan aktivitas-aktivitas belajar lain yang dapat menunjukkan bahwa para siswa (mahasiswa) memahami pelajaran atau kuliahnya. Ketiga, guru (dosen) memberikan umpan balik yang mendorong para siswa (mahasiswa) belajar lebih lanjut. Keempat, guru (dosen) mengaktifkan para siswa (mahasiswa) agar mereka saling mengajari, saling menjadi sumber pengajaran. Kelima, guru (dosen) mengaktifkan 
para siswa (mahasiswa) agar mereka menjadi pemilik aktivitas belajar mereka sendiri, agar mereka bertanggung atas hal ihwal belajar mereka sendiri. Lima strategi ini memperjelas guru (dosen) dan siswa (mahasiswa) dalam menerapkan AaL.

\section{Perkembangan Lanjut}

Perkembangan selanjutnya adalah penerapan AoL, AfL dan AaL dalam keseimbangan baru dengan proporsi AaL yang paling besar dan pemerkayaan ide-ide AaL. Penerapannya langsung dilakukan oleh guru atau dosen dalam bentuk aktivitas-aktivitas di dalam dan di luar kelas-kelas mereka dan juga dilakukan oleh pemerintah-pemerintah dalam bentuk pembuatan kebijakan-kebijakan evaluasi pendidikan. Penerapan ini tentu memperkaya, terutama, ide-ide AaL yang relatif baru dan membutuhkan pematangan dan penyempurnaan.

2007. Di Inggris, Harry Torrance (2007) meneliti pergeseran praktik evaluasi pendidikan di program-program persiapan pendidikan vokasi, pelatihan kerja dan pendidikan orang dewasa. Pergeseran itu berlangsung pada dataran empiris dari AoL melewati AfL menuju AaL.

2009. Setelah meneliti penerapan AaL, AoL dan AfL oleh guru-guru di sekolah di Amerika Serikat, MacMath, Wallace dan Chi (2009) menulis bahwa AaL meningkatkan kemampuan siswa untuk mentransfer pengetahuan ke dalam tindakan guna menghasilkan karya nyata. Namun, penerapan AaL di sini masih berorientasi pada produk, bukan pada proses belajar, padahal AaL jelas berorientasi pada peningkatan proses belajar.

Di Selandia Baru, Hume dan Coll (2009) dan Mutch (2012) memperkaya khazanah AaL. Praktik AaL dalam konteks pendidikan Selandia Baru menghasilkan kurikulum yang berbasis pada pengalaman siswa (student-experienced curriculum) yang berbeda dengan kurikulum Science in the New Zealand Curriculum (SiNZC). Perbedaan ini mendorong Hume dan Coll untuk memberi saran agar para pengambil kebijakan konsisten dalam merumuskan dan menerapkan kebijakan evaluasi pendidikan.

2010. Selanjutnya, penelitian Volante (2010) di dua sekolah dasar dan menengah di Ontario, Kanada menunjukkan bahwa kebanyakan guru masih mengutamakan AoL dibandingkan AfL dan AaL. Sebab, para pemimpin sekolah memiliki pemahaman yang masih rendah tentang AfL dan AaL, sehingga kebijakannya belum berorientasi pada AfL dan AaL. Akibatnya, guru-gurunya belum berorientasi pada AfL dan AaL dalam melakukan evaluasi. Pada waktu itu, disusun pula panduan AfL dan AaL untuk sekolahsekolah kelas 1-12 di Ontario, Growing Success: Assessment, Evaluation and Reporting 
in Ontario Schools (2010). Hasil penelitian Volante serupa dengan hasil penelitian Saefurrohman (2015) di Indonesia yang memperlihatkan bahwa guru-guru bahasa Inggris di sekolah menengah pertama masih mengutamakan AoL daripada AfL dan AaL.

Pemahaman yang rendah tentang AfL dan AaL mengindikasikan bahwa sosialisasi AfL dan AaL perlu dimaksimalkan. Terutama, AaL sebagai gagasan yang relatif baru barangkali belum dikenal oleh semua pemangku kepentingan (stakeholder) pendidikan dan, memang sebagaimana dikatakan Earl (2003) di atas bahwa AoL masih sangat mendominasi evaluasi pendidikan. Maka, perlu dilakukan sosialisasi AaL, pelatihan dan semacamnya di seluruh dunia agar semua pemangku kepentingan pendidikan lebih memahami, teristimewa AaL, dan kemudian menerapkan AaL dengan proporsi yang paling besar.

2011. Gibbons dan Kankkonen (2011) membuat instrumen-instrumen AaL dalam bidang pendidikan olahraga. Menarik untuk mencermati swa-refleksi dan asesmen sejawat yang dilakukan siswa dalam bidang olahraga.

2012. Sementara itu, Mutch (2012) mengatakan bahwa kebijakan pendidikan di Selandia Baru memberi ruang pada tiga hal yang berkaitan dengan asesmen, yakni peningkatan, akuntabilitas dan keberlanjutan. Istilah-istilahnya adalah assessment and improvement (berkaitan dengan AfL), assessment and accountability (berkaitan dengan AoL), dan assessment and sustainability (berkaitan dengan AaL). Mutch memandang AfL bertujuan untuk meningkatkan aktivitas belajar, sedangkan AoL untuk mempertanggungjawabkan hasil belajar, dan AaL untuk menjaga kelangsungan belajar.

Lebih lanjut, Mutch menjelaskan bahwa terdapat enam prinsip dalam kebijakan evaluasi pendidikan di Selandia Baru yang memfasilitasi penerapan tiga paradigma evaluasi pendidikan. Pertama, siswa berada di pusat aktivitas belajar-mengajar. Kedua, kurikulum mendukung evaluasi. Ketiga, mengembangkan kemampuan asesmen (assessment capability) sangat krusial untuk meningkatkan proses dan hasil belajar. Keempat, sistem asesmen bersifat akuntabel. Kelima, bukti-bukti dari beragam sumber menghasilkan respons yang lebih akurat. Keenam, asesmen yang efektif bergantung pada interaksi dan relasi yang berkualitas. Lima prinsip ini, seturut Mutch, memungkinkan AaL, AfL dan AoL diterapkan secara bersama-sama di Selandia Baru.

Hickey, Taasoobshirazi dan Cross (2012) meneliti penerapan AaL dalam programprogram pendidikan astronomi, biologi dan ekologi. Ini membuktikan bahwa AaL bisa diterapkan dalam berbagai bidang ilmu. 
Clark (2012) menekankan self-regulated learning (SRL) sebagai bagian dari AfL dan AaL. Dalam SRL, siswa mengatur dan mengelola aktivitas belajarnya sendiri. AaL identik dengan SRL, dan SRL membutuhkan kemampuan metakognisi yang tinggi.

Fletcher dan Shaw (2012) meneliti bagaimana siswa-siswa kelas 2, 4 dan 6 memperlihatkan keterlibatan mereka dalam asesmen sebagai proses belajar, AaL. Dengan AaL semacam itu, perilaku, emosi dan kognisi para siswa tersebut benar-benar terlibat dalam aktivitas belajar.

2013. Berry (2013) menggagas konsep roda AaL (AaL wheel) untuk memasyarakatkan AaL di kalangan pemangku kepentingan pendidikan. Pertama, istilahistilah dalam $\mathrm{AaL}$ diubah jadi lebih populer dan mudah dipahami untuk mengubah pemahaman dan persepsi masyarakat tentang AaL. Kedua, persepsi dan harapan masyarakat terhadap asesmen berubah. Ketiga, praktik-praktik asesmen pun berubah menuju AaL. Tiga bagian lingkaran AaL ini menggelinding terus menuju peningkatan aktivitas belajar dan mengajar.

2014. Lee dan Mak (2014) mengembangkan langkah-langkah AaL dalam pendidikan bahasa.

Dann (2014) mencatat tiga hal penting dalam penerapan AaL, yakni memahami umpan balik, memahami gap belajar (learning gap), dan mengeksplorasi kosa kata dalam asesmen. Di sini, guru perlu mengurangi fokusnya pada umpan balik yang spesifik dan bersifat mengatur, tetapi memaksimalkan fokusnya pada bagaimana siswa menafsirkan dan memahami umpan balik yang siswa buat sendiri dan bagaimana para siswa mengerti kosa kata-kosa kata dalam asesmen.

Wyatt-Smith, Klenowski dan Colbert (2014) mengedit buku tentang desain asesmen pendidikan untuk mendukung aktivitas belajar yang berkualitas. AoL, AfL dan AaL merupakan bagian penting dalam membuat desain asesmen pendidikan semacam itu.

2015. Hay, Tinning dan Engstrom (2015) menyebut AaL dengan istilah assessment as pedagogy dan melaporkan hasil penelitian mereka dalam pendidikan olahraga bahwa AaL membuahkan hasil belajar yang lebih baik. Syaratnya, AaL diposisikan sebagai bagian penting dari kurikulum dan perencanaan pendidikan.

Pada 2015, Ricky Lam mempublikasikan hasil penelitian pustakanya tentang AaL dalam kelas menulis (writing) dan menunjukkan tabel karakteristik AaL, AfL dan AoL. Tabel ini serupa dengan tabel yang dibuat oleh Sin Wang Chong (2017), tetapi terdapat beberapa perbedaan antara kedua ahli tersebut. 
Sudiyanto, Kartowagiran dan Muhyadi (2015) mengembangkan model AaL pada pelajaran akuntansi di sekolah menengah kejuruan (SMK). Model ini memiliki enam komponen, yaitu tujuan, tugas terstruktur, swa-asesmen, asesmen sejawat, pengamatan terhadap aktivitas siswa, dan umpan balik. Model AaL berhasil meningkatkan kompetensi akuntansi siswa.

2016. Laveault dan Allal (2016) juga sedikit mengupas AaL dan lebih banyak membahas AfL, serta menyoroti regulasi dan peran guru dalam melakukan asesmen untuk mendukung aktivitas belajar siswa. Selama guru tidak mengikuti regulasi-regulasinya yang memfasilitasi AfL, AfL tidak akan terlaksana dengan baik. Jika AfL tidak terlaksana dengan baik, proses belajar pun tidak akan meningkat secara signifikan dan, pada gilirannya, hasil belajarnya juga tidak meningkat.

Almqvist, Vinge, Vakeva dan Zanden (2016) mengikuti Torrance (2007) dan menunjukkan pergeseran evaluasi pendidikan ke arah AaL dalam pelajaran musik di Norwegia dan Swedia.

DeLuca dkk. (2016) membuat instrumen literasi asesmen dengan mengacu pada AoL, AfL dan AaL dalam menyusun item tujuan asesmen.

Fletcher (2016) meriset manfaat praktik AaL bagi siswa-siswa di Australia. Siswasiswa yang diidentifikasi bermotivasi dan berprestasi rendah berhasil meningkatkan motivasi dan prestasi mereka dengan melakukan AaL.

Cheng dan Fox (2017) mengelaborasi penerapan asesmen, termasuk AoL, AfL dan AaL, dalam pembelajaran bahasa.

2018. Wanner dan Palmer (2018) menulis bahwa swa-asesmen dan asesmen sejawat perlu dirancang dan diterapkan dengan saksama agar menjadi alat esesmen formatif yang efektif. Kemampuan mahasiswa untuk memberikan umpan balik kepada temannya dan bimbingan dosen secara terus-menerus sangat dibutuhkan. Swa-asesmen dan asesmen sejawat tidak mudah untuk dilakukan oleh dosen dan mahasiswa, tetapi penting dan diperlukan untuk pendidikan tinggi abad ke-21.

Li (2018) meneliti penerapan AaL, khususnya swa-asesmen, pada kuliah penerjemahan. Hasil penelitian mengungkap bahwa akurasi swa-asesmen mahasiswa berkorelasi positif dengan asesmen yang dilakukan dosennya, bahwa akurasi swa-asesmen makin lama makin meningkat, bahwa swa-asesmen meningkatkan sikap positif mahasiswa terhadap aktivitas belajar. 
2017. Sadeghi dan Rahmati (2017) memberikan bukti empiris bahwa penerapan AaL, AfL dan AoL secara terpadu telah meningkatkan pembelajaran dan asesmen dalam level teoretis dan praktis.

2019. Di Australia, Cumming, Kleij dan Adie (2019) menyatakan bahwa perubahan kebijakan evaluasi pendidikan tentang AfL dan asesmen untuk pertanggungjawaban (assessment for accountability) belum berhasil memperbaiki aktivitas mengajar dan aktivitas belajar. Maka, harus ada satu kesatuan antara pembuatan kebijakan, praktik mengajar, dan bukti penelitian. Cumming, Kleij dan Adie sedikit mengulas AaL.

2020. Sein, Rashid, Meka, Amiel dan Pluta (2020) dalam penelitian mereka membuat panduan berbasis bukti empiris untuk mengimplementasikan AfL dan AaL dalam sistem asesmen pengetahuan pra-klinis. Panduan ini membantu para mahasiswa belajar, menyintesiskan, menguasai dan mengingat materi kuliah dalam jangka panjang, sehingga mereka dapat menerapkan pengetahuan medis mereka ketika berpraktik sebagai paramedis. Implementasi AfL dan AaL ini membutuhkan perubahan budaya asesmen pada seluruh civitas akademika.

AaL, juga AfL dan AoL serta proporsinya kiranya akan terus berkembang di masa mendatang. Lazimnya perkembangan ilmu, akan muncul ide-ide baru tentang tiga paradigma evaluasi pendidikan. Bahkan, barangkali akan muncul pula paradigma evaluasi atau asesmen pendidikan yang baru untuk mengatasi masalah-masalah pendidikan dan memperbaiki kualitas pendidikan.

\section{SIMPULAN}

Paradigma evaluasi atau asesmen pendidikan di sini bertalian dengan aktivitas belajar. AoL/EoL atau evaluasi sumatif bertujuan untuk mengevaluasi hasil belajar, sementara AfL/EfL untuk memperbaiki aktivitas belajar mengajar, dan AaL/EaL untuk mengembangkan SRL siswa. Ketiganya saling melengkapi dengan proporsi keseimbangan yang berubah seiring dengan perkembangan zaman. Dalam keseimbangan tradisional, proporsi AoL/EoL paling besar, sedangkan dalam keseimbangan baru, proporsi AaL/EfL paling besar untuk meningkatkan kualitas proses dan hasil belajar mengajar dan pendidikan secara keseluruhan.

Perkembangan tiga paradigma selama hampir dua dasawarna itu dibagi jadi dua: awal dan lanjut. Perkembangan awalnya merupakan fase pembentukan ide AaL yang secara bersamaan menunjukkan kejelasan perbedaan-perbedaan antara AoL/EoL, AfL/EfL dan AaL/EaL. Pada fase awal ini, para ahli mengeksplorasi tiga paradigma itu secara 
teoretis. Eksplorasi empiris berlangsung pada fase perkembangan lanjut yang memperkaya ide-ide, terutama, AaL. Bukti-bukti ilmiah empiris menunjukkan kelebihan dan kelemahan AfL dan AaL menuju fase perkembangan berikutnya di masa depan.

Penelitian pustaka ini tidak mencakup seluruh publikasi tentang tiga paradigma evaluasi pendidikan level kelas itu. Penelitian ini membatasi diri hanya dengan menggunakan perspektif $\mathrm{AaL} / \mathrm{EaL}$ untuk memetakan perkembangan tiga paradigma tersebut. Konsekuensinya, pustaka yang diteliti hanyalah literatur-literatur yang membahas AaL/EaL beserta AoL/EoL dan AfL/EfL.

\section{SARAN}

Penelitian-penelitian berikutnya perlu menggunakan perspektif AoL/EoL dan AfL/EfL untuk memetakan perkembangan tiga paradigma evaluasi pendidikan. Perlu juga diteliti penerapan AaL/EaL dengan swa-asesmen, SRL dan metakognisi siswa atau mahasiswa dalam seluruh mata pelajaran atau mata kuliah secara cermat untuk mematangkan konsep dan model AaL/EaL mengingat paradigma ketiga ini masih relatif baru.

\section{DAFTAR PUSTAKA}

-------. 2010. Growing Success: Assessment, Evaluation and Reporting in Ontario Schools. http://www.edu.gov.on.ca/eng/policyfunding/GrowSuccess.pdf

Almqvist, C. F., Vinge, J., Vakeva, L., dan Zanden, O. 2016. “Assessment as Learning in Music Education: the Risk of 'Criteria Compliance' Replacing 'Learning' in the Scandinavian Countries”. Research Studies in Music Education Volume 39 Issue 1, halaman $1-16$.

Berry, R. 2013. "The Assessment as Learning (AaL) Framework for Teaching and Learning: The AaL Wheel". Assessment \& Learning Issue 2, halaman 51-70.

Berry. R. 2008. Assessment for Learning. Aberdeen: Hong Kong University Press.

Black, P. dan Wiliam, D. 1998. "Assessment and Classroom Learning". Assessment in Education Volume 5 Number 1, halaman 7-74.

Black, P. dan Wiliam, D. 2018. "Classroom Assessment and Pedagogy". Assessment in Education Volume 25 Issue 6, halaman 1-25.

C.G.A., 1970. "The Research Gap". The Journal of Higher Education Volume 41 Issue 3, halaman 228-232. 
Cheng, L. dan Fox, J. 2017. Assessment in the Language Classroom: Teachers Supporting Student Learning. London: Palgrave.

Chong, S. W. 2017. Three Paradigms of Classroom Assessment: Implications for Written Feedback Research. Language Assessment Quarterly Volume 15 Issue 4, halaman $1-18$.

Clark, I. 2012. "Formative Assessment: Assessment is for Self-Regulated Learning". Education Psychology Review 24, halaman 205-249.

Cookson, . 2017. "Assessment Terms Half a Century in the Making and Unmaking: from Conceptual Ingenuity to Definitional Anarchy". Assessment \& Evaluation in Higher Education Volume 43 Issue 6, halaman 1-13.

Cookson, C. J. 2017. "Assessment Terms Half a Century in the Making and Unmaking: from Conceptual Ingenuity to Definitional Anarchy". Assessment \& Evaluation in Higher Education Volume 43 Issue 6, halaman 1-13.

Cumming, J. J., Kleij, F. M. V. D., dan Adie, L. 2019. “Contesting educational assessment policies in Australia". Journal of Education Policy Volume 34 Issue 6, halaman $1-22$.

Dann, R. 2002. Promoting Assessment as Learning: Improving the Learning Process. London: RoutledgeFalmer.

Dann, R. 2014. “Assessment as Learning: Blurring the Boundaries of Assessment and Learning for Theory, Policy and Practice". Assessment in Education: Principles, Policy \& Practice Volume 21 Issue 2, halaman 149-166.

DeLuca, C., Valiquette, A., Coombs, A., LaPointe-McEwan, D., dan Luhanga, U. 2016. "Teachers' Approaches to Classroom Assessment: a Large-Scale Survey". Assessment in Education: Principles, Policy \& Practice Volume 25 Issue 4, halaman $1-21$.

Earl, L. 2003. Assessment as Learning: Using Classroom Assessment to Maximise Student Learning. Thousand Oaks, CA: Corwin Press.

Earl, L. 2013. Assessment as Learning: Using Classroom Assessment to Maximise Student Learning. Second Edition. Thousand Oaks, CA: Corwin Press.

Earl, L. dan Katz, S. 2006. Rethinking Classroom Assessment with Purpose in Mind: Assessment for Learning, Assessment as Learning, Assessment of Learning. Manitoba: Minister of Education, Citizenship and Youth.

Falchikov, N. 2005. Improving Assessment through Student Involvement: Practical Solutions for Aiding Learning in Higher and Further Education. Oxon: RoutledgeFalmer. 
Fletcher, A. dan Shaw, G. 2012. "How does Student-Directed Assessment Affect Learning? Using Assessment as a Learning Process". International Journal of Multiple Research Approaches Volume 6 Issue 3, halaman 245-263.

Fletcher, A. K. 2016. "Exceeding Expectations: Scaffolding Agentic Engagement through Assessment as Learning". Educational Research Volume 58 Issue 4, halaman $400-419$.

Gibbons, S. L. dan Kankkonen, B. 2011. Assessment as learning in physical education: making assessment meaningful for secondary school students. Physical \& Health Education Journal. Winter.

Hattie, J. dan Jaeger, R.1998. "Assessment and Classroom Learning: a Deductive Approach". Assessment in Education Volume 5 Number 1, halaman 111-122.

Hay, P., Tinning, R., dan Engstrom, C. 2015. “Assessment as Pedagogy: a Consideration of Pedagogical Work and the Preparation of Kinesiology Professionals". Physical Education and Sport Pedagogy Volume 20 Issue 1, halaman 31-44.

Hickey, D. T., Taasoobshirazi, G., dan Cross, D. 2012. "Assessment as Learning: Enhancing Discourse, Understanding, and Achievement in Innovative Science Curricula". Journal of Research in Science Teaching Volume 49 Number 10, halaman 1240-1270.

Hume, A. dan Coll, R. K. 2009. "Assessment of Learning, for Learning, and as Learning: New Zealand Case Studies". Assessment in Education: Principles, Policy \& Practice Volume 16 Number 3, halaman 269-290.

Lam, R. 2015. "Assessment as Learning: Examining a Cycle of Teaching, Learning, and Assessment of Writing in the Portfolio-Based Classroom". Studies in Higher Education Volume 41 Issue 11, halaman 1-18.

Laveault, D. dan Allal, L. (Eds.). 2016. Assessment for Learning: Meeting the Challenge of Implementation. Cham: Springer.

Lee, I. dan Mak, P. 2014. "Assessment as Learning in the Language Classroom". Assessment \& Learning Issue 3, halaman 66-78.

Li, X. 2018. "Self-Assessment as 'Assessment as Learning' in Translator and Interpreter Education: Validity and Washback". The Interpreter and Translator Trainer Volume 12 Issue 1, halaman 1-20.

MacMath, S., Wallace, J. dan Chi, X. 2009. "CurriculumIntegration: Opportunities to Maximize Assessment as, of, and for Learning". McGill Journal of Education Volume 44 Number 3, halaman 451-465.

Mutch, C. 2012. "Assessment for, of and as Learning: Developing a Sustainable Assessment Culture in New Zealand Schools". Policy Futures in Education Volume 10 Number 4, halaman 374-385. 
Rust, J. dan Golombok, S. 2009. Modern Psychometrics: the Science of Psychological Assessment Third Edition. East Sussex: Routledge.

Sadeghi, K. dan Rahmati, T. 2017. "Integrating Assessment as, for, and of Learning in a Large-Scale Exam Preparation Course”. Assessing Writing 34, halaman 50-61.

Saefurrohman. 2015. "Classroom Assessment Preference of Indonesian Junior High School Teachers in English as Foreign Language Classes". Journal of Education and Practice Volume 6 Number 36, halaman 104-110.

Scriven, M. 1967. "The Methodology of Evaluation” dalam R.W. Tyler, R.W. Gagne dan M. Scriven (Eds.), American Educational Research Association Monograph Series on Curriculum Evaluation, Vol .1: Perspectives of Curriculum Evaluation. Rand McNally, halaman 39-83.

Sein, A. S., Rashid, H., Meka, J., Amiel, J., dan Pluta, W. 2020. “Twelve Tips for Embedding Assessment for and as Learning Practices in a Programmatic Assessment System”. Medical Teacher Volume 42 Issue 11, halaman 1-7.

Serafini, F. 2001. Three Paradigms of Assessment: Measurement, Procedure, and Inquiry. The Reading Teacher. Volume 54 Number 4, halaman 384-393.

Stiggins, R. J. 2002. “Assessment Crisis: The Absence Of Assessment FOR Learning”. Phi Delta Kappan June 2002, halaman 758-765.

Sudiyanto, Kartowagiran, B., dan Muhyadi. 2015. "Pengembangan Model Assessment as Learning Pembelajaran Akuntansi di SMK". Jurnal Penelitian dan Evaluasi Pendidikan Volume 19 Nomor 2, halaman 189-201.

Torrance, H. 2007. "Assessment as Learning? How the Use of Explicit Learning Objectives, Assessment Criteria and Feedback in Post-Secondary Education and Training Can Come to Dominate Learning." Assessment in Education Volume 14 Number 3, halaman 281-294.

Volante, L. 2010. "Assessment of, for, and as Learning within Schools: Implications for Transforming Classroom Practice". Action in Teacher Education Volume 31 Number 4, halaman 66-75.

Wanner, T. dan Palmer, E. 2018. "Formative Self-and Peer Assessment for Improved Student Learning: the Crucial Factors of Design, Teacher Participation and Feedback". Assessment \& Evaluation in Higher Education Volume 43 Issue 7, halaman $1032-1047$.

Wyatt-Smith, C., Klenowski, V. dan Colbert, P. 2014. Designing Assessment for Quality Learning Volume 1. Heidelberg: Springer.

Xiao, Y. dan Watson, M. 2017. "Guidance on Conducting a Systematic Literature Review". Journal of Planning Education and Research Volume 40 Issue 1, halaman $1-20$. 